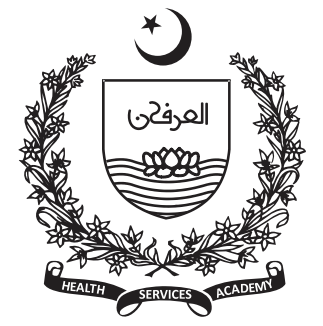

\title{
Prevalence, impact, management practices and factors associated with dysmenorrhea among students of Akhtar Saeed Medical \& Dental College Lahore
}

Saadia Maqbool ${ }^{1}$, Iram Manzoor ${ }^{2}$, Nidal Fatima ${ }^{3}$, Saroosh Tahir ${ }^{3}$, Hammad Shahid ${ }^{3}$, Muhammad Usman Hanif ${ }^{3}$, Mohammad Ali Haider ${ }^{3}$, Noreen Tarar $^{3}$

\section{Abstract}

1Senior Demonstrator Community Medicine Department, Akhtar Saeed Medical \& Dental College Lahore

${ }^{2}$ Head of Community Medicine Department and Director Medical Education, Akhtar Saeed Medical \& Dental College Lahore

3Final year MBBS student, Akhtar Saeed Medical \& Dental College Lahore

Corresponding Author: Saadia Maqbool Email: maqboolsaadia@yahoo.com

Background: Dysmenorrhea is an important health issue of young adult females that badly affects their quality of life and academic performance. This study aimed to determine prevalence, impact, management practices and factors associated with dysmenorrhea among medical students.

Methods: This analytical cross-sectional study was conducted in Akhtar Saeed Medical \& Dental College Lahore from August 2020 to December 2020. Using Cochran's sample size calculator and rounding off, sample size of 400 female students was calculated. Convenience sampling technique was used. A selfconstructed questionnaire was used which was designed after extensive literature search. Pain intensity was estimated using Visual Analogue Scale (VAS). Data were entered and analyzed in SPSS version 23. Chi square test was applied to find association between variables. A p-value of $<0.05$ was considered statistically significant.

Results. Mean age of participants was $21.07 \pm 2.58$ years. Prevalence of dysmenorrhea was $79.5 \%$. Statistically significant association was found between dysmenorrhea and participant's age ( $p$ value $=0.002)$, marital status $(p$ value $=0.001)$, family income $(p$ value $=<0.001)$, age of menarche (p value $=<0.001)$, days of bleeding $(p$ value $=0.009)$ and regularity of cycle $(p$ value $=<0.001$ ). Mostly participants used combinations of remedies. Rest was the most commonly used remedy to relieve pain. Impact of dysmenorrhea included social withdrawal, inability to prepare for exam, difficulty in carrying out daily activities and absence from college.

Conclusion. Prevalence of dysmenorrhea was $79.5 \%$. Statistically significant association was found between dysmenorrhea and participant age, marital status, family income, age of menarche, days of bleeding and regularity of cycle. Alone or together, taking rest was the most commonly used remedy to relieve pain. Dysmenorrhea negatively affected quality of life.

Keywords: Dysmenorrhea, impact, management, menstrual symptoms 
Prevalence, impact, management practices and factors associated with dysmenorrhea among students of Akhtar Saeed Medical \& Dental College Lahore

\section{Introduction}

$\mathrm{M}$ enstruation is a physiological phenomenon that symbolizes fertility of a woman (1). Females experience a variety of physical and psychological symptoms during menstrual period like pain, headache and fatigue (2). Over production of prostaglandins and ischemic contractions of the uterus are the major contributory factors of dysmenorrhea (3). Although menstruation is a normal physiological phenomenon, dysmenorrhea is very common problem in young adult females (4). Globally, as many as $90 \%$ of adolescent females and more than $50 \%$ of menstruating women report suffering from it, with $10-20 \%$ of them describing the pain as severe and distressing (5). Dysmenorrhea was reported by $61.6 \%$ participants in a research conducted in India (6). A cross sectional study conducted in public sector medical colleges in Lahore revealed prevalence of dysmenorrhea was $78.6 \%$ (7). Many factors are associated with dysmenorrhea including menarche at early age, longer duration of menstrual flow, heavy menstrual bleeding, smoking and positive family history (8).

Pain and associated symptoms usually begin before the onset of menstrual flow or later and persist for few hours or days. Different options including pharmacological and non-pharmacological management approaches such as taking non-steroidal anti-inflammatory drugs, herbal products, hot liquids, specific diet, yoga, heating pad and rest have been used to reduce the intensity of pain (9).

Dysmenorrhea affects social life of an individual. It has a negative effect on academic and professional performance, social relationships and daily activities. The effects of painful periods include absenteeism, anxiety, depression, decreased work output and social withdrawal, contributing to decreased quality of life (10). Severe dysmenorrhea may badly affect the quality of life, sometimes leading to disability and inefficiency. It can cause mental and psychological health problems in some of the females resulting in reduced participation in different social activities (11).

Moderate to severe pain that affects routine activities and does not respond to pharmacological treatment can be a sign of underlying pelvic disease like endometriosis which may require medical check-up and appropriate diagnosis of possible underlying pathology (12).
Although dysmenorrhea affects physical and social well-being of females, there is a low tendency to seek health care advice for this problem, may be due to the perception of dysmenorrhea being a normal condition rather than a health issue (13).

For any developing country, medical students are regarded a valuable future human resource. To maintain focus on studies, their physical and psychological wellbeing is very important. Any health issue which can affect their academic and professional performance must be explored. It is important to know about prevalence, impact and factors associated with dysmenorrhea. Insufficient knowledge about magnitude and impacts of this health issue may lead to lower level of awareness and insufficient treatment. This information can be used to plan and implement strategies regarding health education of young females about effective and scientifically proven management practices and training of health care providers to deal this issue. In Pakistan, available data regarding its prevalence and impact on health status and social wellbeing among women is limited. This study aimed to find out prevalence, impact and factors associated with dysmenorrhea among medical students.

\section{Methodology}

This analytical cross-sectional study was conducted in Akhtar Saeed Medical \& Dental College Lahore from August 2020 to December 2020. Sample size was calculated using Cochran's sample size formula. Keeping 5\% precision and $95 \%$ confidence level a sample size of 385 was calculated. After rounding off, final sample size came out to be 400 participants. Approval from ethical review board of Akhtar Saeed Medical \& Dental College was taken (IRB certificate no M-19/050/-CM). Convenience sampling technique was used. All healthy female students of various medical programmes (MBBS, BDS, Pharma-D and Allied Health Sciences) $17-25$ years of age, who were willing to participate were included. Female students more than 25 years and those who were not willing to participate were excluded. A self-constructed, pre tested questionnaire was used. Research questionnaire was designed after extensive literature search by modifying the questions used in previous studies. After review by one gynecologist, one biostatistician and two public health specialists, questionnaire was piloted on 20 female students of Akhtar Saeed Medical \& Dental College. The questionnaire was found to be reliable (Cronbach's alpha value was 0.73 ). 
Operational definition of dysmenorrhea was set as painful, cramping sensation in the lower abdomen or lower back with onset around the time of initiation of menstruation. The Visual Analogue Scale (VAS) is a scale used to determine the pain intensity experienced by individuals (14). Pain intensity was estimated using Visual Analogue Scale (VAS); 1-3 score as mild pain, 46 score as moderate pain and 7-10 score as severe pain. Data were entered and analyzed in SPSS version 23. Categorical variables were tabulated in frequency and percent distribution. Mean and standard deviation were calculated for continuous variable. Chi square test of significance was applied to find association between variables. A p-value of $<0.05$ was taken as statistically significant.

\section{Results}

Mean age of participants was $21.07 \pm 2.58$ years. Out of total 400 students, $348(87 \%)$ were single while $52(13 \%)$ were married. Most of the participants $(57.3 \%)$ were day scholar while rest $42.8 \%$ were residing in hostel. The mean menarche age was $13.16 \pm 1.74$ years. Out of 400 students, 318(79.5\%) had dysmenorrhea. Prevalence of dysmenorrhea among various socio demographic categories are mentioned in Table 1

Among total participants, 131(32.8\%) told that the onset of pain is before start of bleeding, while rest $187(46.8 \%)$ reported that they experience pain during menstrual flow. Most of the participants, i.e 199 (49.75\%) reported that pain lasts for a day while rest feel pain for longer duration.

Higher percentage of dysmenorrhea was observed among participant aged $22-25$ years $(84 \%)$, unmarried females $(82.2 \%)$, whose family income was more than 100000 per month $(85.5 \%)$, who had menarche between 11-14 years $(85.2 \%)$, who had bleeding for 4-7 days $(85.6 \%)$ and who had regular cycles $(84 \%)$. Association between these factors and dysmenorrhea was statistically significant ( $\mathrm{p}$ value $<0.05$ ).

The Visual Analogue Scale (VAS) was used to estimate the intensity of menstrual pain from 0 to 10 . Mild pain was reported by $26(6.5 \%)$, moderate pain by $127(31.8 \%)$ and severe pain by $165(41.2 \%)$ study participants.

Majority of participants used combinations of remedies to relieve pain. Heating pad along with analgesics were used by $24(6 \%)$, home remedies by $46(11.5 \%)$, homeopathic medicine by $27(6.7 \%)$, exercise by $4(1 \%)$, tea \& coffee by $36(9 \%)$, medicine from pharmacy by
Table 1: Socio demographic characteristics of participants

\begin{tabular}{|c|c|c|c|}
\hline CHARACTERISTICS & n (\%) & $\begin{array}{l}\text { DYSMEN- } \\
\text { ORRHEA } \\
\text { PRESENT }\end{array}$ & p value \\
\hline $\begin{array}{l}\text { Age of participant } \\
\text { Up to } 17 \text { years } \\
18-21 \text { years } \\
22-25 \text { years }\end{array}$ & $\begin{array}{l}42(10.5) \\
164(41) \\
194(48.5) \\
\end{array}$ & $\begin{array}{l}25(59.5) \\
130(79.2) \\
163(84)\end{array}$ & $0.002^{*}$ \\
\hline $\begin{array}{l}\text { Marital Status } \\
\text { Married } \\
\text { Single }\end{array}$ & $\begin{array}{l}52(13) \\
348(87)\end{array}$ & $\begin{array}{l}32(61.5) \\
286(82.2)\end{array}$ & $0.001^{*}$ \\
\hline $\begin{array}{l}\text { Area of residence } \\
\text { Day Scholar } \\
\text { Hostel resident }\end{array}$ & $\begin{array}{l}229(57.25) \\
171(42.75)\end{array}$ & $\begin{array}{l}176(76.9) \\
142(83)\end{array}$ & 0.13 \\
\hline $\begin{array}{l}\text { Family income } \\
\text { Less than } 50000 \text { per } \\
\text { month } \\
50000-100000 \quad \text { per } \\
\text { month } \\
\text { More than } 100000 \text { per } \\
\text { month }\end{array}$ & $\begin{array}{l}65(16.25) \\
135(33.75) \\
200(50)\end{array}$ & $\begin{array}{l}41(63.1) \\
106(78.5) \\
171(85.5)\end{array}$ & $<0.001^{*}$ \\
\hline $\begin{array}{l}\text { Age at Menarche } \\
7-10 \text { years } \\
11-14 \text { years } \\
15-18 \text { years } \\
\text { More than } 18 \text { years }\end{array}$ & $\begin{array}{l}22(5.5) \\
236(59) \\
116(29) \\
26(6.5)\end{array}$ & $\begin{array}{l}18(81.8) \\
201(85.2) \\
87(75) \\
12(46.2)\end{array}$ & $<0.001^{*}$ \\
\hline $\begin{array}{ll}\text { Family history of } \\
\text { dysmenorrhea } \\
\text { Present } \\
\text { Absent }\end{array}$ & $\begin{array}{l}67(16.75) \\
333(83.25)\end{array}$ & $\begin{array}{l}50(74.6) \\
268(80.5)\end{array}$ & 0.28 \\
\hline $\begin{array}{l}\text { Duration of bleeding } \\
1-3 \text { days } \\
4-7 \text { days } \\
\text { More than } 8 \text { days }\end{array}$ & $\begin{array}{l}65(16.25) \\
202(50.5) \\
133(33.25) \\
\end{array}$ & $\begin{array}{l}47(72.3) \\
173(85.6) \\
98(73.7)\end{array}$ & $0.009^{*}$ \\
\hline $\begin{array}{l}\text { Length of menstrual } \\
\text { cycle } \\
\text { Less than } 21 \text { days } \\
21-24 \text { days } \\
25-29 \text { days } \\
\text { More than } 30 \text { days }\end{array}$ & $\begin{array}{l}26(6.5) \\
148(37) \\
165(41.25) \\
61(15.25)\end{array}$ & $\begin{array}{l}19(73.7) \\
123(83.1) \\
125(75.8) \\
51(83.6)\end{array}$ & 0.27 \\
\hline $\begin{array}{l}\text { Pattern of menstrual } \\
\text { cycle } \\
\text { Regular } \\
\text { Irregular }\end{array}$ & $\begin{array}{l}269(67.25) \\
131(32.75)\end{array}$ & $\begin{array}{l}226(84) \\
92(70.2)\end{array}$ & $0.001^{*}$ \\
\hline
\end{tabular}

*Statistically significant

$14(3.5 \%)$, rest along with heating pad by $81(20.3 \%)$, rest and home remedies by $45(11.3 \%)$ and rest with tea or coffee by $41(10.3 \%)$ study participants. 
Prevalence, impact, management practices and factors associated with dysmenorrhea among students of Akhtar Saeed Medical \& Dental College Lahore

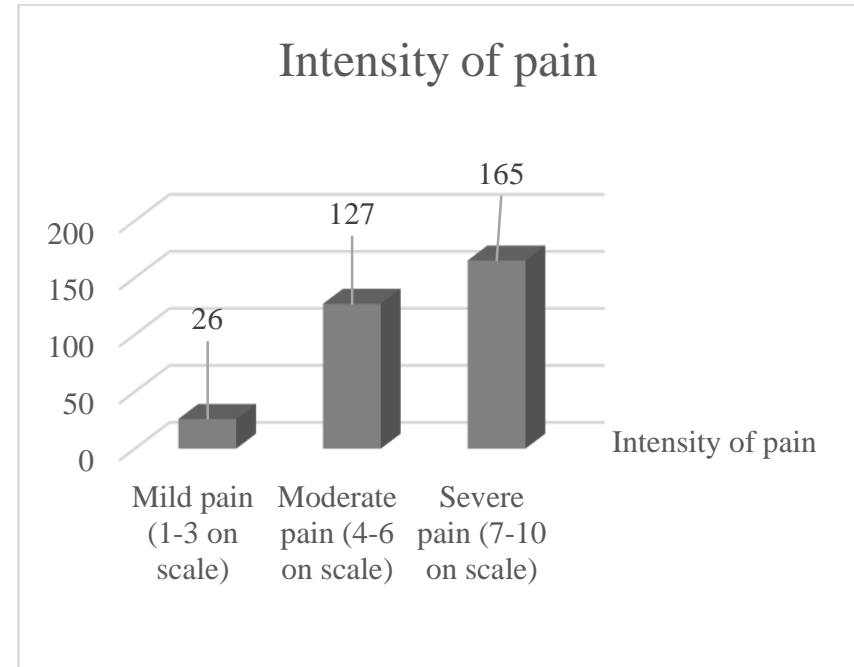

Figure 1: Intensity of pain $(n=318)$

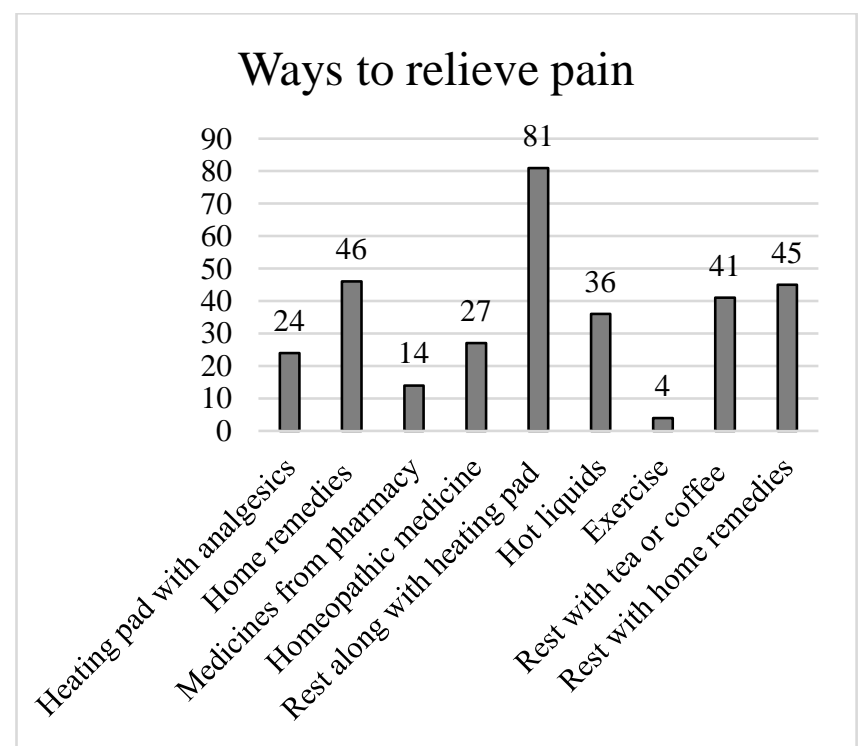

Figure 2: Ways to relieve pain $(n=318)$

Impact of dysmenorrhea on daily activities of participants is mentioned in table 2. More than one third participants $(38.3 \%)$ used to take leave from college due to dysmenorrhea. Only $8.5 \%$ were able to carry out daily activities while rest were either unable to carryout daily activities or were able to do occasionally. About $26 \%$ female students revealed that they withdraw themselves from friends and family. Among total participants, $37 \%$ were not able to prepare for test/exam due to pain. Only $35.5 \%$ were able to manage physical activities during menstruation while $44 \%$ were not able to do so due to pain. About 50.3\% and $9.3 \%$ of total participants thought that their quality of life is poor or very poor respectively due to dysmenorrhea.

Table 2: Impact of dysmenorrhea $(n=318)$

\begin{tabular}{|l|l|l|}
\hline $\begin{array}{l}\text { IMPACT OF } \\
\text { DYSMENORRHEA }\end{array}$ & $\begin{array}{l}\text { NO } \\
\text { RESPONDENTS } \\
\text { (n) }\end{array}$ & $\begin{array}{l}\text { \% AMONG } \\
\text { TOTAL } \\
\text { PARTICIPANTS }\end{array}$ \\
\hline $\begin{array}{l}\text { Used to take leave } \\
\text { from college }\end{array}$ & \\
Yes & 153 & 38.3 \\
No & 165 & 41.3 \\
\hline $\begin{array}{l}\text { Able to carry out } \\
\text { daily activities }\end{array}$ & & \\
Always & 34 & 8.5 \\
Occasionally & 244 & 61 \\
No & 40 & 10 \\
\hline $\begin{array}{l}\text { With drawn from } \\
\text { friends / family }\end{array}$ & & \\
Yes & 105 & 26.3 \\
No & 213 & 53.3 \\
\hline Quality of life & & \\
Good & 80 & 20 \\
Poor & 201 & 50.3 \\
Very poor & 37 & 9.3 \\
\hline Able to prepare for & & \\
test/exam & 170 & 42.5 \\
Yes & 148 & 37 \\
No & 142 & \\
\hline Able to do physical & & \\
activities & & \\
Yes & & \\
No & & \\
\hline
\end{tabular}

\section{Discussion}

The findings of this study revealed that the prevalence of dysmenorrhea was high (79.5\%). However, it is comparable to the reported values in researches conducted in other countries. Similar results were observed in Japanese college students, participants with around $79 \%$ have experienced pain in menstruation phase (15). A systematic review which included 38 studies conducted in countries having low, middle and high income, showed the prevalence of dysmenorrhea as high as $71.1 \%$ (16). A study conducted in India among Pharma students of similar age group revealed prevalence of dysmenorrhea as $82 \%$ (17).

Although pain is subjective feeling, most of the participants of this study reported the intensity of pain as moderate or severe. Mild pain was reported by $26(6.5 \%)$, moderate pain by $127(31.8 \%)$ and severe pain by $165(41.2 \%)$ participants. Another study conducted 
among Spanish female university students described prevalence of dysmenorrhea as $74.8 \%$ with $38.3 \%$ participants having severe menstrual pain and 58\% having moderate pain. In both studies, majority of participants described intensity of their pain as moderate or severe (18).

Dysmenorrhea was more common in respondents aged 22-25 years. Similar findings were revealed in another study conducted among Egyptian females aged 12-25 years. Researchers mentioned that increased age was of the most potential risk factors for dysmenorrhea (19).

This study reflected that being unmarried or single is an associated factor of dysmenorrhea. Results of study at Benin also found that single women were 1.3 times more likely to have dysmenorrhea (20).

Results of the study reflected that participants who bleed for 4-7 days showed highest prevalence of dysmenorrhea. In a study conducted in India, girls having menstrual flow for more than 5 days had 1.9 times more chance of having dysmenorrhea (21).

High prevalence of dysmenorrhea was observed in respondents who had menarche before 14 years of age. Heba et al also concluded that in Palestinian university students, dysmenorrhea was significantly associated with menarche below 14 years of age (22).

Most of the participants who had regular cycles reported dysmenorrhea. This finding was similar to a study conducted among medical students of South India which showed higher percentage of participants $(82.7 \%)$ having regular cycles reported dysmenorrhea. Moreover, available scientific knowledge suggests that dysmenorrhea is more common in ovulatory cycles which are usually regular (23).

This study reflected there is no significant association between positive family history and dysmenorrhea. Findings of another study conducted among female students at Kuwait are different. Respondents having positive family history of dysmenorrhea, had higher odds of having dysmenorrhea (24). Some researchers have suggested that women with a family history of dysmenorrhea can experience menstrual pain due to behavior learned from their mothers and sisters (18).

Majority of participants used combinations of remedies to relieve pain. Alone or in combination with other remedies, taking rest $(41.9 \%)$ was the most commonly used remedy. The other remedies used to relieve pain were heating pad along with analgesics, home remedies, homeopathic medicine, exercise, hot liquids like tea \& coffee and pharmaceutical medicine. Results of a research conducted in India also described different approaches to relieve pain such as rest by $38 \%$, over the counter medication $6.1 \%$, use of heating pad $17.6 \%$, exercise $1.8 \%$ and special food and drink $8.5 \%$ (25).

Dysmenorrhea has great impact on educational activities and daily routine of females. In this study $38.3 \%$ participants used to take leave from college due to dysmenorrhea. About two third participants were facing difficulty to carryout daily activities. The results are comparable to a study conducted in Saudi Arabia which showed that $38.9 \%$ of the respondents reported that they restrict daily activities while $44.9 \%$ restrict social activities during their menstrual period and about class attendance of $34 \%$ was affected (26).

In current study, a significant percentage of participants $(26.3 \%)$ reported social withdrawal due to dysmenorrhea. Results of another study conducted in Turkey showed percentage of social withdrawal was $36.7 \%$. Life style and degree of social and personal stress can be regarded as potential reasons for this variation (27).

Dysmenorrhea negatively affects quality of life. Most of the respondents reported poor or very poor quality of life due to pain during menstruation. Researchers in a study conducted in Riyadh, Saudi Arabia also described that dysmenorrhea had a negative effect on quality of life (28).

\section{Conclusion}

Prevalence of dysmenorrhea was 79.5\%. Statistically significant association was found between dysmenorrhea and participant age, marital status, family income, age of menarche, days of bleeding and regularity of cycle. Majority of participants used combinations of remedies to relieve pain. Alone or in combination with other remedies, taking rest was the most commonly used remedy to relieve pain. Dysmenorrhea negatively affected quality of life. Impact of dysmenorrhea included social withdrawal, inability to prepare for exam, difficulty to carryout daily activities and leave from college. In young female medical students, moderate to severe dysmenorrhea that affects their routine, academic and professional activities, requires professional attention and proper diagnosis of possible underlying pelvic disease. Knowledge about magnitude of this health issue, its impact and associated factors will help health care providers to accurately diagnose and manage dysmenorrhea. Information and awareness are required to optimize the use of existing management practices. 
Prevalence, impact, management practices and factors associated with dysmenorrhea among students of Akhtar Saeed Medical \& Dental College Lahore

\section{Acknowledgments:}

The authors are thankful to Momal Khan and Asma Akif for their support and facilitation.

\section{Source of funding:}

None

Conflict of Interest:

No conflict of interest to be declared.

\section{References}

1. Erbil N, Felek N, Karakaşlı E. The relationship between attitudes towards menarche and current attitudes towards menstruation of women: A comparative study. Journal of Human Sciences. 2015 Nov 13;12(2):1120-30.

2. Zareen S, Rehman HU, Noor M, Nisa S, Yasmin M, Bahadar $S$ et al. Physical and mental effects of menstruation cycle in relation to ten diverse professions among females of district Kohat, KP Pakistan. J Entomol Zool Stud. 2016;4(4):1225-7.

3. Kannan P, Cheung KK, Lau BW. Does aerobic exercise induced-analgesia occur through hormone and inflammatory cytokine-mediated mechanisms in primary dysmenorrhea?. Medical hypotheses. 2019 Feb 1;123:50-4.

doi:https:/ / doi.org/10.1016/j.mehy.2018.12.011

4. Vlachou E, Owens DA, Lavdaniti M, Kalemikerakis J, Evagelou E, Margari N,et al. Prevalence, wellbeing, and symptoms of dysmenorrhea among university nursing students in Greece. Diseases. 2019 Mar;7(1):5. doi: 10.3390/diseases7010005

5. Rabiu A, Abubakar IS, Garba I. Dysmenorrhea and menstrual patterns among adolescent school girls in Kano. New Nigerian Journal of Clinical Research. 2019 Jan 1;8(13):30. doi: 10.4103/nnjcr.nnjcr_3_18

6. Kandpal J, Sharma MD, George U. Occurrence of Menstrual Irregularities among Adolescent Girls in Selected Area, Dehradun, Uttarakhand. EXECUTIVE EDITOR. 2019 Jan;10(1):27-31. doi: https://doi.org/10.37506/ijphrd.v10i1.7801

7. Ashraf T, Riaz S, Atta S, Ikram A, Shehzadi HK. Prevalence of dysmenorrhea and impact on young medical students; a cross sectional study on students of medical colleges of Lahore, Pakistan. Rawal Medical Journal. 2020 Apr;45(2):430-3.

8. De VS, Soliman A, Bernasconi S, Bianchin L, Bona G, Bozzola M, et al. Primary Dysmenorrhea in Adolescents: Prevalence, Impact and Recent Knowledge. Pediatric endocrinology reviews: PER. 2015 Dec;13(2):512-20.

9. Mahvash, A. Eidy, and K. Mehdi, "The effect of physical activity on primary dysmenorrhea of female university students," World Applied Sciences Journal. 2012;17(10):1246-52.

10. Amu EO, Bamidele JO. Prevalence of menstrual disorders among adolescent girls in Osogbo, South Western Nigeria. Int $\mathrm{J}$ Adolesc Med Health.
2014;26(1):101-6. doi: https://doi.org/10.1515/ijamh2013-0500

11. Hennegan J, Shannon AK, Rubli J, Schwab KJ, MelendezTorres GJ. Women's and girls' experiences of menstruation in low-and middle-income countries: A systematic review and qualitative metasynthesis. PLoS medicine. 2019 May 16;16(5):e1002803. doi: https://doi.org/10.1371/journal.pmed.1002803

12. Ghanghoriya V, Patel K, Markam R. Prevalence of dysmenorrhoea and its effect on quality of life among nursing students. Int J Reprod Contracept Obstet Gynecol 2018;7: 2129-35.

13. Ramos-Pichardo JD, Ortega-Galán ÁM, Iglesias-López MT, Abreu-Sánchez A, Fernández-Martínez E. Why Do Some Spanish Nursing Students with Menstrual Pain Fail to Consult Healthcare Professionals?. Int J Environ Res Public Health. 2020 Jan;17(21):8173.doi: https://doi.org/10.3390/ijerph17218173

14. Abreu-Sánchez A, Parra-Fernández ML, Onieva-Zafra MD, Ramos-Pichardo JD, Fernández-Martínez E. Type of dysmenorrhea, menstrual characteristics and symptoms in nursing students in southern spain. In Health care. 2020 Sep (Vol. 8, No. 3, p. 302). Multidisciplinary Digital Publishing Institute. doi https://doi.org/10.3390/healthcare8030302

15. Yamamoto K, Okazaki A, Sakamoto Y, Funatsu M. The relationship between premenstrual symptoms, menstrual pain, irregular menstrual cycles, and psychosocial stress among Japanese college students. J Physiol Anthropol. 2009;28(3):129-36. doi: https://doi.org/10.2114/jpa2.28.129

16. Armour M, Parry K, Manohar N, Holmes K, Ferfolja T, Curry $\mathrm{C}$,et al. The prevalence and academic impact of dysmenorrhea in 21,573 young women: a systematic review and meta-analysis. Journal of Women's Health. 2019 Aug 1;28(8):1161-71. doi: https://doi.org/10.1089/jwh.2018.7615

17. Sudhakar P. Prevalence of Primary Dysmenorrhea in Pharma Students: A Cross-Sectional Study. Sch Acad J Pharm. 2021:6-12

18. Fernández-Martínez E, Onieva-Zafra MD, ParraFernández ML. Lifestyle and prevalence of dysmenorrhea among Spanish female university students. PLoS One. 2018 Aug 10;13(8):e0201894. doi: https://doi.org/10.1371/journal.pone.0201894

19. Arafa AE, Senosy SA, Helmy HK, Mohamed AA. Prevalence and patterns of dysmenorrhea and premenstrual syndrome among Egyptian girls (12-25 years). Middle East Fertility Society Journal. 2018 Dec 1;23(4):486-90.

doi: https://doi.org/10.1016/j.mefs.2018.01.007

20. Vodouhe MV, Imorou RS, Atade R, Salifou K, Vignonzan U, Hounkponou NF, et al. Prevalence and Factors Associated with Dysmenorrhea in Parakou, Benin. Open J Obstet Gynecol. 2020 Aug 6;10(08):1000. 
21. Kural M, Noor NN, Pandit D, Joshi T, Patil A. Menstrual characteristics and prevalence of dysmenorrhea in college going girls. J Family Med Prim Care. 2015 Jul;4(3):426. doi: https://dx.doi.org/10.4103\%2F22494863.161345

22. Helwa HA, Mitaeb AA, Al-Hamshri S, Sweileh WM. Prevalence of dysmenorrhea and predictors of its pain intensity among Palestinian female university students. BMC women's health. 2018 Dec 1;18(1):18. 20

23. Manjunath SM, Lakshmipathi BS, Ravi Kumar S. Prevalence and treatment patterns of dysmenorrhea among female medical students:a questionnaire based study at KIMS, Koppal. International Journal of Basic \& Clinical Pharmacology. 2020 Dec;9(12):1844. doi: https:// doi.org/10.18203/2319-2003.ijbcp20205121

24. Al-Matouq S, Al-Mutairi H, Al-Mutairi O, Abdulaziz F, Al-Basri D, Al-Enzi M, et al. Dysmenorrhea among highschool students and its associated factors in Kuwait. BMC pediatrics. 2019 Dec;19(1):1-2.

25. Omidvar S, Bakouei F, Amiri FN, Begum K. Primary dysmenorrhea and menstrual symptom in Indian female students: prevalence, impact and management. Glob J Health Sci. $2016 \quad$ Aug;8(8):135. doi: https://dx.doi.org/10.5539\%2Fgjhs.v8n8p135

26. Abdel-Salam DM, Alnuman RW, Alrwuaili RM, Alrwuaili GA, Alrwuaili EM. Epidemiological aspects of dysmenorrhea among female students at Jouf University, Saudi Arabia. Middle East Fertility Society Journal. 2018 Dec 1;23(4):435-9. doi: https:// doi.org/10.1016/j.mefs.2018.08.001

27. Bilir E, Yıldız Ş, Yakın K, Ata B. The impact of dysmenorrhea and premenstrual syndrome on academic performance of college students, and their willingness to seek help. Turk J Obstet Gynecol. 2020 Sep;17(3):196. doi: https://dx.doi.org/10.4274\%2Ftjod.galenos.2020.97266

28. Hashim RT, Alkhalifah SS, Alsalman AA, Alfaris DM, Alhussaini MA, Qasim RS, et al. Prevalence of primary dysmenorrhea and its effect on the quality of life amongst female medical students at King Saud University, Riyadh, Saudi Arabia. Saudi Med J. 2020 Mar 1;41(3):2839. doi:10.15537/smj.2020.3.24988 